\title{
Synthesis of a new tricylic ring system: $[1,2,3]$ triazolo[1,5-b]cinnolinium salt
}

\author{
Gyöngyvér Ágnes Vaskó, Zsuzsanna Riedl, Orsolya Egyed, and György Hajós* \\ Chemical Research Center of the Hungarian Academy of Sciences, H-1025 Budapest, \\ Pusztaszeri út 59, Hungary \\ E-mail: ghajos@chemres.hu
}

\section{Dedicated to Professor Csaba Szántay on the occasion of his $80^{\text {th }}$ birthday}

\begin{abstract}
Synthesis of the first representative of the linearly fused [1,2,3]triazolo[ $[1,5-b]$ cinnolinium heteroaromatic cation as a quaternary salt is reported. Improved reaction conditions for preparation of some precursors have been elaborated. Reaction of the new heteroaromatic salt with nucleophiles resulted in regioselective formation of zwitterionic products.
\end{abstract}

Keywords: Ring closure, cinnoline, nucleophilic addition, bridge-head nitrogen atom, zwitterions, negative solvatochromy

\section{Introduction}

In the frame of our investigations on bridge-head nitrogen containing fused azolium salts we reported the synthesis of the linearly fused $[1,2,3]$ triazolo[1,5-b]isoquinolinium salt $\left(\mathbf{1}, \mathrm{R}^{1}=\right.$ alkyl and aryl group, Ar $=$ phenyl or substituted phenyl group) ${ }^{1}$. Study of the reactivity of this quaternary salt (1) revealed that in reactions with various nucleophiles (e.g. with $\mathrm{NuH}=$ morpholine) regioselective addition at C-9 takes place to yield stable pseudobase-type products (2). This finding prompted us to extend the investigations to an aza-derivative of $\mathbf{1}$ containing a nitrogen atom in position 9. This structural change excludes the possibility of an attack of the nucleophile in this particular position. In this paper we report our efforts to synthesize this designed $[1,2,3]$ triazolo[1,5- $b]$ cinnolinium salt and to explore its reactivity with nucleophilic reagents. 


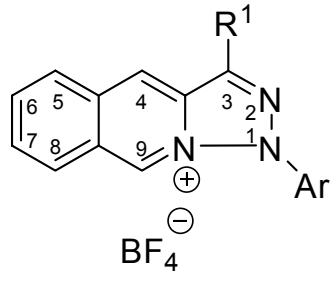

1
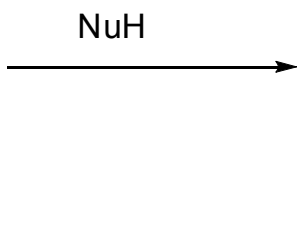<smiles>[R]C1=NN([Al])N2C1=Cc1ccccc1C2N</smiles>

2

\section{Results and Discussion}

According to the earlier established protocol ${ }^{2}$, the synthesis of the desired model compound was planned by oxidative cyclization of cinnoline-3-ketones. Our literature survey indicated that very few procedures leading to such ketones were published ${ }^{3,4}$, among which the method described by Al-Alwadi et al. ${ }^{4}$ a few years ago seemed the most suitable for our purpose. These authors found that such ketones (6) can be obtained via a 3-step pathway starting from substituted benzophenones (3). Thus, $\mathbf{3}$ was reacted first with dimethylformamide dimethylacetal to give an aminoenone (4), this compound was then reacted with phenyldiazonium salt to afford the hydrazone $\mathbf{5}$ and, finally, cyclization reaction under strongly acidic conditions resulted in formation of the cinnoline ketone (6).<smiles>[R]c1ccc(C(C)=O)cc1</smiles>

3<smiles>[R]c1ccc(C(=O)/C=C/N(C)C)cc1</smiles>

4

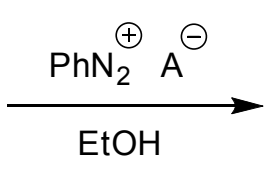

$\mathrm{EtOH}$<smiles>[R]c1ccc(C(=O)/C(C=O)=N/N(I)c2ccccc2)cc1</smiles>

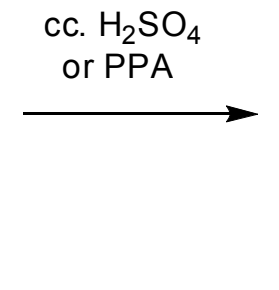<smiles>[R]c1ccc(C(=O)c2cc3ccccc3nn2)cc1</smiles>

6

While reproduction of the first reaction step $\left(\right.$ i.e. $\mathbf{3} \rightarrow \mathbf{4}$ ) took place in excellent yield, ${ }^{5}$ we had to encounter some difficulties with the subsequent two reaction steps: rather low yields and intensive decompositions were experienced. As a result of an ongoing search for suitable reaction conditions for the desired synthesis, however, we have found that by the help of two modifications both transformations can be carried out in satisfactory and well reproducible yields. 
The first modification was that instead of in situ preparation of the diazonium salt in the second reaction step, crystalline phenyldiazonium fluoroborate $\left(\mathrm{A}=\mathrm{BF}_{4}\right)^{6}$ was used and, thus, hydrazones 5a-d were obtained in high yields. As to the final ring closure reaction we have found, furthermore, that extenstion of the reaction time to $40 \mathrm{~min}$ and exclusive application of polyphosphoric acid results in a dramatic increase of the yields of 6a-d. This successful preparative result allowed also the synthesis of two new compounds: the $p$-bromo substituted $\mathbf{5 e}$ and 6e. Some data (yield, $\mathrm{mp}$ ) of the products prepared by the improved methodology are compiled in Table 1., whereas the modified reaction conditions are described in the Experimental Section for the new derivatives $5 \mathbf{e}$ and $\mathbf{6 e}$

Table 1. Improved reaction conditions and yields with the synthesis of the hydrazones $\mathbf{5}$ and ketones 6

\begin{tabular}{ccccc}
\hline $\mathbf{5}$ & $\mathrm{R}$ & Yield $(\%)$ & $\mathrm{Mp}\left({ }^{\circ} \mathrm{C}\right)$ & $\begin{array}{c}\text { Literature } \\
\mathrm{Mp}\left({ }^{\circ} \mathrm{C}\right)\end{array}$ \\
\hline $\mathbf{a}$ & $\mathrm{H}$ & 80 & $96-98$ & $82-84$ \\
$\mathbf{b}$ & $\mathrm{Cl}$ & 80 & $136-138$ & $135-137$ \\
$\mathbf{c}$ & $\mathrm{OMe}$ & 70 & $139-140$ & $141-143$ \\
$\mathbf{d}$ & $\mathrm{NO}_{2}$ & 82 & $188-190$ & $173-175$ \\
$\mathbf{e}$ & $\mathrm{Br}$ & 84 & $143-144$ & - \\
\hline & & & & \\
\hline $\mathbf{6}$ & $\mathrm{R}$ & Yield $(\%)$ & $\mathrm{Mp}\left({ }^{\circ} \mathrm{C}\right)$ & Literature \\
& & & & $\mathrm{Mp}\left({ }^{\circ} \mathrm{C}\right)$ \\
\hline $\mathbf{a}$ & $\mathrm{H}$ & 71 & $135-136$ & $138-139$ \\
$\mathbf{b}$ & $\mathrm{Cl}$ & 71 & $151-152$ & $152-154$ \\
$\mathbf{c}$ & $\mathrm{OMe}$ & 47 & $190-191$ & $189-191$ \\
$\mathbf{d}$ & $\mathrm{NO}$ & 91 & $214-216$ & $210-212$ \\
$\mathbf{e}$ & $\mathrm{Br}$ & 77 & $150-152$ & - \\
\hline
\end{tabular}

Treatment of $p$-nitrophenyl ketone (6d) with p-bromophenylhydrazine hydrochloride in ethanolic hydrochloric acid afforded arylhydrazone 7 as orange crystals. Oxidative cyclization of other related hydrazones to triazolium salts are generally carried out by $N$-bromosuccinimide ${ }^{2}$. While application of this reagent in the present case, unfortunately, failed, treatment of 7 with 2,4,4,6-tetrabromocyclohexa-2,5-dienone (8) - easily obtainable by bromination of 1,3,5tribromophenol and also commercially available - successfully resulted in the desired cyclization and gave the fused triazolium bromide 9 as yellow crystals in modest yield. 


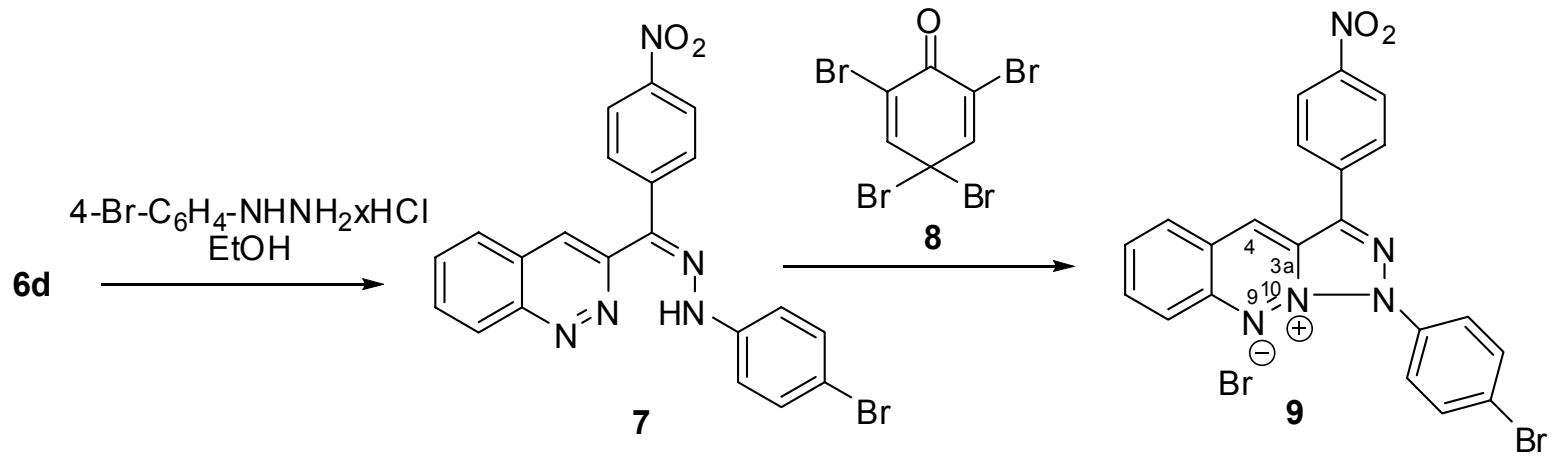

Comparison of the UV spectra of 7 and 9 revealed that a significant change of the absorbances occurred (blue shift of the first maximum by $35 \mathrm{~nm}$ ) which clearly indicates the substantial change of the chromophore. Appearance of the downfield ${ }^{1} \mathrm{H}-\mathrm{NMR}$ shift (singlet at $10.64 \mathrm{ppm}$ ) is also in accordance with the presence of the positively charged heteroaromatic pyridazine moiety.

Two nucleophilic reagents: pyrrolidine and sodium methoxide have been selected for investigation of reactivity of the new heteroaromatic salt 9 . These reactions have been carried out in acetonitrile at room temperature. In both cases a zwitterionic addition product (10 and 11, respectively) separated from the reaction mixture. The most significant spectral property of these products was the presence of a proton attached to the saturated carbon atom in position 4 appearing at 5.8 and $6.6 \mathrm{ppm}$, respectively, whereas all routine analytical data (elemental analysis, MS) were in entire agreement with these structures.

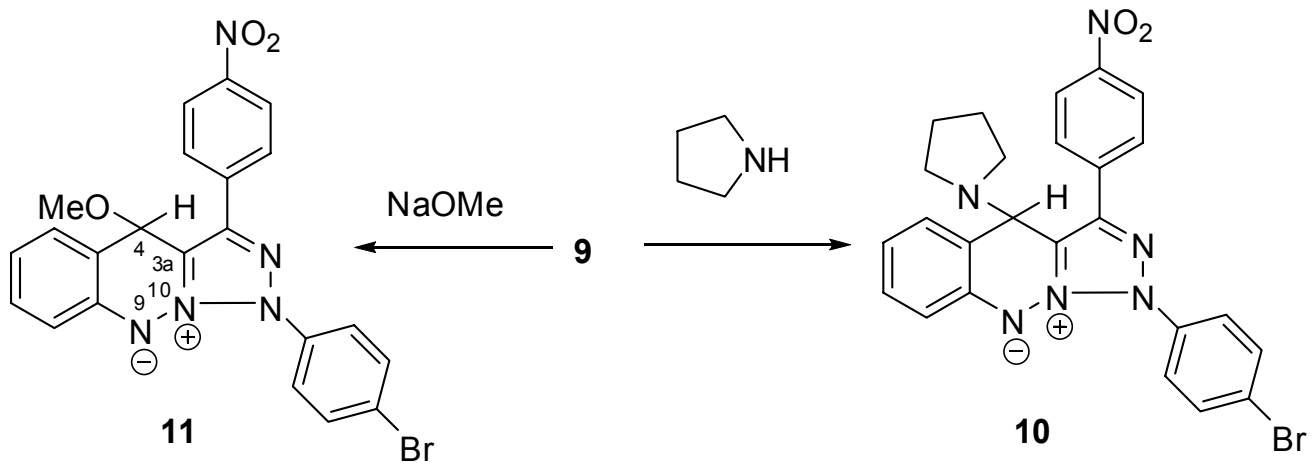

An interesting spectroscopic feature of zwitterionic compounds is the negative solvatochromy $^{7}$, i.e. a significant red shift of the first maximum in UV/VIS when changing a polar solvent for an apolar one. This has also been detected for derivative $\mathbf{1 0}$ as shown in Fig 1. The interesting finding of this regioselective addition reveals that position 4 as indicated by the strongly downfield NMR shift of the attached proton is electron-withdrawn enough to accept the nucleophilic heteroatom and to form a new sigma bond. The addition is obviously facilitated by the presence of N-9 atom which is able to bear two lone electron pairs and, thus, to become negatively charged. In other words, it is the C4-C3a-N10-N9 1,2-diazadiene structural moiety in 
9 that plays an important role in this selective nucleophilic addition; there are several literature records that 1,2-diazadienes easily react with nucleophiles at the terminal $\mathrm{C} 4$ atom $^{8}$.

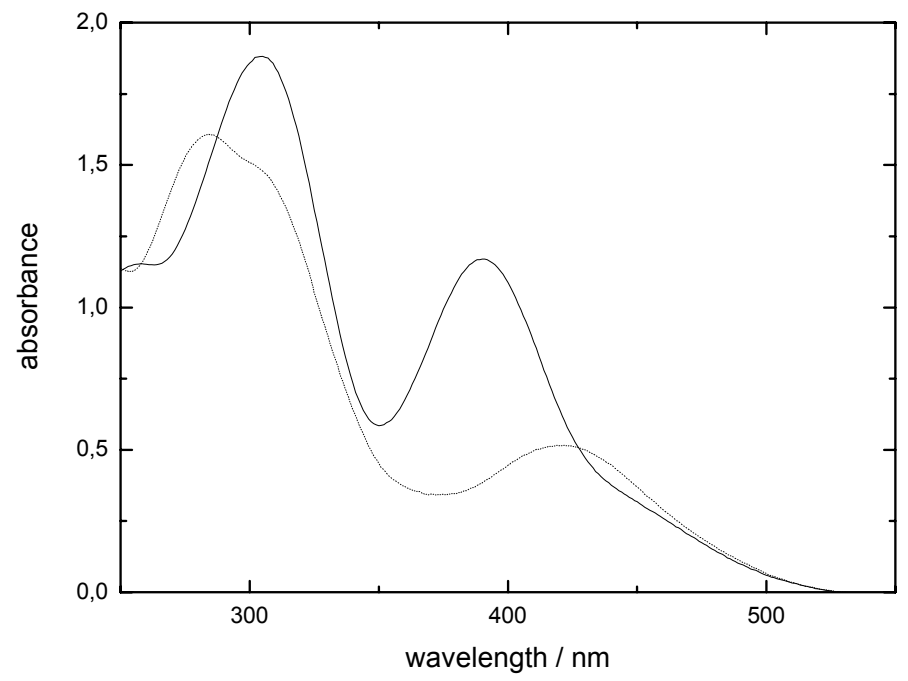

Figure 1. UV spectrum of 10: a red shift of $29 \mathrm{~nm}$, approximately appears in the spectrum recorded in a dichloromethane solution ( ---- ) compared to that of the acetonitrile solution (-).

Although the title new tricyclic heteroaromatic salt has been synthesized successfully, extenstion of this methodology to ketones bearing substituents other than nitro group on the phenyl moiety failed. In these cases the hydrazones related to 7 can not be isolated from the reaction mixture because subsequent rapid spontaneous conversions. Study of these transformations is in progress and the results will be published later.

\section{Experimental Section}

General Procedures. Melting Points were determined on a Kofler apparatus and are uncorrected. The IR spectra were recorded on a Thermo Nicolet Avatar 320 FT-IR spectrometer and the UV spectra were measured on a ThermoSpectronic Unicam UV 500 spectrophotometer. The NMR spectra were determined on a Varian Unity Inova spectrometer $(200 \mathrm{MHz}$ and 400 $\mathrm{MHz}$ for ${ }^{1} \mathrm{H}$ and $100 \mathrm{MHz}$ for ${ }^{13} \mathrm{C}$ ). The elemental analysis has been carried out with an Elementar Vario EL III apparatus.

(E)-3-(4-Bromophenyl)-3-oxo-2-(2-phenylhydrazono)propanal (5e). A solution of (E)-1-(4bromophenyl)-3-(dimethylamino)prop-2-en-1-one (4e) $(9.7 \mathrm{~g}, 38.2 \mathrm{mmol})$ in EtOH (110 mL) 
was cooled down to $0-(-5){ }^{\circ} \mathrm{C}$ and stirred with a mechanical stirrer. To this solution a cold suspension of phenyldiazonium fluoroborate $(8.03 \mathrm{~g}, 42 \mathrm{mmol}$, in $50 \%$ aqueous EtOH, $140 \mathrm{~mL}$ ) was added in portions so that the temperature of the reaction mixture remained below $0{ }^{\circ} \mathrm{C}$. After complete addition of the diazonium salt the reaction mixture was stirred at $0{ }^{\circ} \mathrm{C}$ for $10 \mathrm{~min}$, and allowed to warm up to room temperature. It was then stirred for additional $4 \mathrm{~h}$, the precipitated product was filtered off and recrystallized from acetonitrile to give orange yellow crystals: 12.65 g (84\%). mp: $143-144{ }^{\circ} \mathrm{C}$. IR (KBr, cm $\left.{ }^{-1}\right): 3129,2863,1650,1633,1589,1518,1271 ;{ }^{1} \mathrm{H}$ NMR $\delta\left(\mathrm{CDCl}_{3}\right): 7.22$ (m, 1H, H4”), 7.37 (m, 2H, H2", H6”), 7.41 (m, 2H, H3”, H5”), 7.63 (m, 2H,

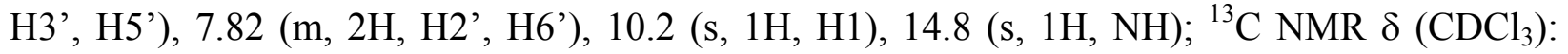
116.8 (2C), 126.9, 127.4, 130.1 (2C), 131.4 (2C), 131.6, 132.1 (2C), 132.3, 136.0, 189.6, 190.2. Anal. Calcd for $\mathrm{C}_{15} \mathrm{H}_{11} \mathrm{BrN}_{2} \mathrm{O}_{2}$ (331.16): C, 54.40; H, 3.35; N, 8.46; Found: C, 54.15; H, 3.42; N, 8.40 .

(4-Bromophenyl)(cinnolin-3-yl)methanon (6e). To preheated polyphosphoric acid (45 g, inner temperature $\left.100{ }^{\circ} \mathrm{C}\right)(E)-3$-(4-bromophenyl)-3-oxo-2-(2-phenylhydrazono)propanal (5e, $3.79 \mathrm{~g}$, $11.45 \mathrm{mmol}$ ) was added. The mixture was heated to $118-120{ }^{\circ} \mathrm{C}$ (inner temperature) and stirred for $40 \mathrm{~min}$. The reaction mixture was poured onto ice water $(200 \mathrm{~mL})$ and extracted with chloroform (3x100 mL). The organic layer was dried over sodium sulphate, filtered and evaporated. The residue was recrystallized from acetonitrile to give yellow crystals: $2.77 \mathrm{~g}$ (77\%). mp: $150-152{ }^{\circ} \mathrm{C}$. IR (KBr, cm $\left.{ }^{-1}\right): 3041,2924,1655,1588,1324,1249,1226 ;{ }^{1} \mathrm{H} \mathrm{NMR}$ $\delta\left(\mathrm{CDCl}_{3}\right): 7.69$ (m, 2H, H3', H5'), $7.88(\mathrm{dd}, 1 \mathrm{H}, J=8.5,8 \mathrm{~Hz}, \mathrm{H} 6), 8.04$ (m, 2H, H7, H5), 8.2 (m, 2H, H2', H6'), 8.65 (d, $1 \mathrm{H}, J=8 \mathrm{~Hz}, \mathrm{H} 8), 8.68$ (s, $1 \mathrm{H}, \mathrm{H} 4) ;{ }^{13} \mathrm{C} \mathrm{NMR} \delta\left(\mathrm{CDCl}_{3}\right): 125.7$, 126.2, 128.3, 129.0, 130.2, 131.8 (2C), 132.2, 133.1, 133.3 (2C), 135.2, 151.2, 151.9, 191.4. Anal. Calcd for $\mathrm{C}_{15} \mathrm{H}_{9} \mathrm{BrN}_{2} \mathrm{O}$ (313.15): C, 57.53; H, 2.90; N, 8.95; Found: C,57.21; H,2.98; N,9.03.

(E)-3-((2-(4-Bromophenyl)hydrazono)(4-nitrophenyl)methyl)cinnoline (7). A mixture of cinnolin-3-yl(4-nitrophenyl)methanone (6d, $1.18 \mathrm{~g}, 4.24 \mathrm{mmol})$, ethanol $(50 \mathrm{~mL})$, (4bromophenyl)hydrazine hydrochloride $(1.42 \mathrm{~g}, 6.37 \mathrm{mmol})$, and hydrochlorid acid in ethanol $5 \mathrm{~N}$ $(1 \mathrm{~mL})$ was refluxed for 4.5 hours. The mixture was cooled down and the solid precipitate was collected. The crystals were boiled in ethanol and, after cooling, filtered off to give $1.14 \mathrm{~g}$ yellow crystals, $2.56 \mathrm{mmol}(60 \%)$ of product, $\mathrm{mp}>300^{\circ} \mathrm{C}$. IR $\left(\mathrm{KBr}, \mathrm{cm}^{-1}\right): 3264,3074,1602,1523$, 1484, 1346, 1523, 1111; UV $\lambda(\mathrm{nm})$ in acetonitrile: 342,$228 ;{ }^{1} \mathrm{H}$ NMR $\delta$ (DMSO): 7.24 (m, 2H, H-2", H-6”), 7.44 (m, 2H, H-3", H-5”), 7.72 (m, 2H, H-2', H-6'), 7.97 (dd, 1H, J=7.5, 7 Hz, H6), 8.09 (dd, 1H, J=8.7, 7 Hz, H-7), 8.18 (d, 1H, J=7.5 Hz, H-5), 8.2 (m, 2H, H-3', H-5'), 8.48 (s, $1 \mathrm{H}, \mathrm{H}-4), 8.62$ (d, $1 \mathrm{H}, J=8.7 \mathrm{~Hz}, \mathrm{H}-8), 10.3$ (s, $1 \mathrm{H}, \mathrm{NH}) ;{ }^{13} \mathrm{C}$ NMR $\delta$ (DMSO): $112.6,116.2$ (2C), 124.5 (2C), 126.8, 127.5 (2C), 128.5, 129.1, 129.8, 132.5 (2C), 132.6(2C), 132.7(2C), 138.3, 144.5, 145.0, 147.0, 149.0, 150.5; Anal. Calcd for $\mathrm{C}_{21} \mathrm{H}_{14} \mathrm{BrN}_{5} \mathrm{O}_{2}$ (448.27): C, 56.27; $\mathrm{H}$, 3.15; N, 15.62; Found: C, 56.29; H, 2.79; N, 15.61 .

1-(4-Bromophenyl)-3-(4-nitrophenyl)-1H-[1,2,3]triazolo[1,5-b]cinnolin-10-ium bromide (9).

A mixture of 2,4,4,6-tetrabromocyclohexa-2,5-dienone $(\mathbf{8}, 3.07 \mathrm{~g}, 7.5 \mathrm{mmol})$, and dry dichloromethane $(70 \mathrm{ml})$ was heated to reflux temperature and was added $(E)-3-((2-(4-$ 
bromophenyl)hydrazono)(4-nitrophenyl)methyl)cinnoline (7, $1.12 \mathrm{~g}, 2.5 \mathrm{mmol})$. The reaction mixture was heated under reflux for 1 additional hour. The separated solid was filtered off, it was suspended in nitromethane and heated to reflux and the mixture was filtered. The filtrate was cooled down, cyclohexene $(3 \mathrm{~mL})$ was added whereupon yellow crystals separated which were filtered off to give $360 \mathrm{mg}, 0.683 \mathrm{mmol}(27 \%)$ of product, $\mathrm{mp}>300^{\circ} \mathrm{C}$. IR $\left(\mathrm{KBr}, \mathrm{cm}^{-1}\right): 3021$, 1523, 1485, 1340, 1000, 848; UV $\lambda(\mathrm{nm})$ in acetonitrile: $307,285,222 ;{ }^{1} \mathrm{H}$ NMR $\delta$ (DMSO): 8.09 (m, 2H, H-2”, H-6”), 8.13 (m, 2H, H-3", H-5”), 8.18 (ddd, 1H, J=8, 7.5, 2 Hz, H-7), 8.37 (ddd, 1H, J=8.2, 7.5, 2.5 Hz, H-6), 8.42 (dd, 1H, J=8.2, 2 Hz, H-5), 8.55 (m, 3H, H-2', H-6', H8), 8.63 (m, 2H, H-3', H-5'), 10.64(s, 1H, H-4); ${ }^{13} \mathrm{C}$ NMR $\delta$ (DMSO): 125.7 (2C), 126.3, 126.7, 127.4, 128.7 (2C), 129.3, 129.6, 130.0 (2C), 132.9, 133.1, 133.6, 133.9, 134.0 (2C), 139.3, 140.5, 147.1, 149.8; Anal. Calcd for $\mathrm{C}_{21} \mathrm{H}_{13} \mathrm{Br}_{2} \mathrm{~N}_{5} \mathrm{O}_{2}$ (527.17): C, 47.85; H, 2.49; N, 13.28; Found: C, 45.00; H, 2.59; N, 11.92 .

1-(4-Bromophenyl)-3-(4-nitrophenyl)-4-(pyrrolidin-1-yl)-1,4-dihydro-[1,2,3]triazolo[1,5-

b]cinnolin-10-ium-9-ide (10). Pyrrolidine $(80 \mu \mathrm{l}, 69 \mathrm{mg}, 0.96 \mathrm{mmol})$ was added to a solution of 1-(4-bromophenyl)-3-(4-nitrophenyl)-1H-[1,2,3] triazolo[1,5-b]cinnolin-10-ium bromide (9, 100 $\mathrm{mg}, 0.19 \mathrm{mmol})$ in dry acetonitrile $(7 \mathrm{~mL})$, and the mixture was stirred at room temperature 5 hours. Orange-red crystals separated which were filtered off to give $81 \mathrm{mg}, 0.156 \mathrm{mmol}(82 \%)$ of product, $\mathrm{mp}>300^{\circ} \mathrm{C}$. IR $\left(\mathrm{KBr}, \mathrm{cm}^{-1}\right): 2970,2801,1603,1519,1486,1454,1344,1263$; UV $\lambda$ $(\mathrm{nm})$ in acetonitrile: $390(\log \varepsilon=4.1358), 304(\log \varepsilon=4.350)$, in dichloromethane: $419(\log \varepsilon=$ 4.1638), $294(\log \varepsilon=4.497) ;{ }^{1} \mathrm{H}$ NMR $\delta\left(\mathrm{CDCl}_{3}\right)$ : 1.6 (m, 4H, H-pyrrolidine), 2.38 (m, 4H, Hpyrrolidine), 5.78 (s, 1H, H-4), 7.0 (dd, 1H, J=8.2, 8 Hz, H-6), 7.12-7.18 (m, 2H, H-8, H-5), 7.31 (dd, 1H, J=8.5, 8 Hz), 7.7 (m, 2H, H-2”, H-6”), 8.1 (m, 2H, H-3”, H-5”), 8.32 (m, 2H, H-2', H6'), 8.38 (m, 2H, H-3', H-5'); ${ }^{13} \mathrm{C}$ NMR $\delta\left(\mathrm{CDCl}_{3}\right)$ : 23.1, 47.4, 53.7, 110.1, 116.8, 119.7, 121.2, 123.0, 124.4, 125.6, 128.8, 129.0, 129.7, 132.4, 135.6, 136.3, 142.9, 146.8, 148.5; Anal. Calcd for $\mathrm{C}_{25} \mathrm{H}_{21} \mathrm{BrN}_{6} \mathrm{O}_{2}$ (517.38): C, 58.04; H, 4.09; N, 16.24; Found: C, 57.70; H, 4.04; N, 16.38 .

\section{1-(4-Bromophenyl)-4-methoxy-3-(4-nitrophenyl)-1,4-dihydro-[1,2,3]triazolo[1,5-}

b]cinnolin-10-ium-9-ide (11) A 2M alcoholic sodium methoxide solution (75 $\mu 1,3.5 \mathrm{mg}, 0.06$ mmol) was added to a solution of 1-(4-bromophenyl)-3-(4-nitrophenyl)-1H-[1,2,3]triazolo[1,5b] cinnolin-10-ium bromide $(9,100 \mathrm{mg}, 0.19 \mathrm{mmol})$ in dry acetonitrile $(7 \mathrm{~mL})$, and the mixture was stirred at room temperature 5 hours. Orange-red crystals separated which were filtered off to give $63 \mathrm{mg}, 0.132 \mathrm{mmol}(70 \%)$ of product, $\mathrm{mp}>300^{\circ} \mathrm{C}$. IR $\left(\mathrm{KBr}, \mathrm{cm}^{-1}\right): 3095,2937,1603,1524$, 1488, 1461, 1345, 1053; ${ }^{1} \mathrm{H}$ NMR $\delta\left(\mathrm{CDCl}_{3}\right): 2.9$ (s, 3H, OMe), 6.6 (s, 1H, H-4), 7.1 (ddd, 1H, $J=9,8,2 \mathrm{~Hz}, \mathrm{H}-6), 7.21$ (dd, 1H, J=8.3, $2 \mathrm{~Hz}, \mathrm{H}-8$ ), 7.4 (ddd, 1H, J=8.3, 8, 2 Hz, H-7), 7.47 (dd, 1H, J=9, 2 Hz, H-5), 7.72 (m, 2H, H-2", H-6”), 8.1 (m, 2H, H-3”, H-5”), 8.32 (m, 2H, H-2', H6'), 8.41 (m, 2H, H-3', H-5'); ${ }^{13} \mathrm{C}$ NMR $\delta\left(\mathrm{CDCl}_{3}\right): 51.2,69.2,111.2,116.0,120.6,122.5,123.9$, 124.6 (2C), 125.7 (2C), 128.5 (2C), 129.8, 130.1, 130.6, 132.5 (2C), 133.0, 135.1, 135.5, 145.7. 


\section{Acknowledgements}

Financial supports OTKA T047317, NKFP 1A/005/2004 and project (GVOP-3.2.1-2004-040311/3.0) for elemental analyzer are gratefully acknowledged.

\section{References and Notes}

1. Béres, M.; Hajós, Gy.; Riedl, Zs.; Timári, G.; Messmer, A. Monatshefte 1998, 129, 897.

2. (a) Béres, M.; Hajós, Gy.; Riedl, Zs.; Timári, G,; Messmer, A.; Holly, S.; Schantl J. G., Tetrahedron 1997, 53, 9393. (b) Riedl, Zs.; Hajós, Gy.; Messmer, A.; Kollenz G. J. Heterocyclic Chem. 1993, 30, 819. (c) Bátori, S.; Messmer, A. J. Heterocycl. Chem. 1994, $31,1041$.

3. (a) Amer, A. M.; El-Mobayed, M. M.; Asker, S. Monatshefte, 2004, 135, 595. (b) Turck, A.; Ple, N.; Tallon, V.; Queguiner, G. Tetrahedron, 1995, 51, 13045.

4. Al-Awadi, N. A.; Elnagdi, M. H.; Ibrahim, Y. A.; Kaul, K.; Kumar, A. Tetrahedron, 2001, 57, 1609.

5. Tseng, Sh.-Sh.; Epstein, J. W.; Brabander, H. J.; Francisco, G. J. Heterocycl. Chem. 1987, $24,837$.

6. Hanson, P.; Jones, J. R.; Taylor, A. B.; Walton, P. H.; Timms, A. W. J. Chem. Soc., Perkin Trans. 2 2002, 1135.

7. Reichardt, Ch.; Harbusch-Gornert, E. Liebiegs Ann. Chem. 1983, 721.

8. (a) Abbiati, G.; Arcadi, A.; Attanasi, O. A.; De Crescentini, L.; Rossi, E. Tetrahedron 2001, 57, 2031. (b) Attanasi, O. A.; De Crescentini, L.; Filippone, P.; Giorgi, G.; Mantellini, F.; Mazzanti, A. Synlett 2006, 15, 2403. (c) Schantl, J. G.; Karpellus, P.; Prean, M. Tetrahedron 1982, 38, 2643. (e) Bozzini, S.; Felluga, F.; Nardin, G.; Pizzioli, A.; Pitacco, G.; Valentin, E. J. Chem. Soc., Perkin Trans. 1 1996, 1961. 